\title{
Design and Experimental Characterization of EDFA-Based WDM Ring Networks With Free ASE Light Recirculation and Link Control for Network Survivability
}

\author{
G. Sacchi, S. Sugliani, A. Bogoni, F. Di Pasquale, Member, IEEE, R. Di Muro, R. Magri, G. Bruno, and F. Cavaliere
}

\begin{abstract}
In this paper, we theoretically and experimentally investigate the performance of erbium-doped fiber amplifier (EDFA)-based WDM ring networks with free amplified spontaneous emission (ASE) light recirculation. We show that, with proper network and amplifier design, the lasing light generated by free ASE recirculation within the looped network provides an effective gain clamping technique, ensuring limited signal power excursions under WDM channels add-drop operations. Considering a ring network composed of eight fiber sections and eight EDFAs, maximum signal power overshoots below $2.5 \mathrm{~dB}$ have been measured under 23/24 WDM channels drop. Optical signal-to-noise ratio (OSNR) analysis and bit-error rate (BER) measurement at $10 \mathrm{~Gb} / \mathrm{s}$ confirm acceptable performances and negligible penalties due to polarization effects and relative intensity noise transfer from laser light to WDM signals. We also propose and demonstrate a new link control technique which overcomes the main limiting factors of such networks, respectively, related to OSNR degradation, stability and survivability to fiber and EDFA breakages.
\end{abstract}

Index Terms-Erbium-doped fiber amplifiers (EDFAs), gain clamping, transient effects, WDM optical networks.

\section{INTRODUCTION}

$\mathbf{L}$ OW cost and effective amplifier power transient controls are becoming essential for future WDM metro-core network development. Although new amplification technologies, such as Raman [1] and semiconductor optical amplifiers [2] can provide remarkable performances in terms of gain bandwidth and flexibility, standard erbium-doped fiber amplifiers (EDFAs) are still the most attractive solution as the best tradeoff between cost end performances. When EDFAs are used in add/drop networks [3], or in presence of traffic bursts [4], signal power transients due to the variable input signal load, can cause serious

Manuscript received July 5, 2004; revised November 17, 2004

G. Sacchi, S. Sugliani, and A. Bogoni are with the Photonic Networks National Laboratory, Consorzio Nazionale Interuniversitario per le Telecomunicazioni (CNIT), 56124 Pisa, Italy.

F. Di Pasquale is with Scuola Superiore Sant'Anna di Studi Universitari e Perfezionamento, 56127 Pisa, Italy (e-mail: fabrizio.dipasquale@ cnit.it).

R. Di Muro is with Marconi Corporation plc, New Century Park, CV3 1 HJ Coventry, U.K.

R. Magri and G. Bruno are with Marconi Communications, 56124 Genova, Italy.

F. Cavaliere is with Marconi Photonics Technology Research Center, 56124 Pisa, Italy.

Digital Object Identifier 10.1109/JLT.2005.843471 performance degradation, therefore gain control techniques must be used, which can be either electrical or all-optical.

In WDM ring networks, in which EDFAs are used to compensate the losses of both fiber spans and network elements, closed optical paths can be formed, giving rise to uncontrolled lasing oscillations which can impair network performances under WDM channels add-drop operations [5].

In this paper we demonstrate, by power transients and network performance analysis, that closed cycle lasing can be made stable and used to stabilize reconfigurable WDM networks. Both theory and experiments confirm that an effective all-optical gain clamping technique for EDFA-based WDM ring networks, can be implemented, based on free amplified spontaneous emission (ASE) light recirculation along the ring. We show that proper network and amplifier design can make the system robust to WDM channels add-drop operations providing, at the same time, a cost effective signal power transients control and acceptable optical signal-to-noise ratio (OSNR) performances.

However, although ASE light recirculation can ensure limited power transient under WDM channels add-drop operations, avoiding complex and costly devices and algorithms, optical ring networks based on this gain clamping technique suffer from two main limiting factors.

The first one is related to OSNR degradation; in fact in order to make the network stable under add-drop operations, relatively high span losses between consecutive EDFA are required. It is quite difficult to ensure good network stability and high OSNR at the same time.

The second important limiting factor is that, in case of EDFA and/or fiber breakage, strong signal power excursions are expected because of loss of the clamping mechanism, provided by ASE recirculation.

Here we propose and demonstrate a new link control technique [6], which consists in injecting a laser beam at a given amplifier node of the ring network, and leave it free to circulate in the loop [7]. Although suitable EDFA electronic control strategies can be implemented in order to deal with amplifier and/or fiber breakage, the insertion of this laser beam, being centered around a wavelength where it is desired that a lasing peak is generated, provides at the same time great network robustness in terms of span loss variations, very limited signal power 
transients under add-drop operations, improved OSNR performance and high network survivability in case of fiber or EDFA breakage.

\section{THEORETICAL MODEL}

A dynamic model has been developed and experimentally validated for designing EDFA-based WDM ring networks with ASE light recirculation, also including link control techniques.

The model is similar to the EDFA reservoir model presented in [4] and [8] but also includes ASE light recirculation. It requires easily measured input erbium-doped fiber parameters, such as the spectral absorption and gain coefficients $\alpha(\lambda), g(\lambda)$, the saturation fiber parameter $\xi$ [9] and erbium metastable lifetime $\tau$. The reservoir $\mathrm{r}(\mathrm{t})$ is defined as

$$
r(t)=N_{\operatorname{Er}} A \int_{0}^{L} N_{2}(z, t) d z
$$

where $N_{\mathrm{Er}}$ is the erbium concentration, A is the active fiber cross section, L is the erbium-doped fiber length, and $N_{2}(z, t)=$ $\bar{n}_{2} / N_{\mathrm{Er}}$ is the average metastable level population density $\bar{n}_{2}$, normalized to the erbium concentration $N_{\mathrm{Er}}$. The reservoir dynamics can be described by the following ordinary differential equation

$$
\begin{aligned}
\frac{d r(t)}{d t}=- & \frac{r(t)}{\tau}+\sum_{j=0}^{N+M} \frac{1}{h \nu_{j}} P_{j}(0, t)\left[1-\exp \left(B_{j} r(t)-A_{j}\right)\right] \\
& -\sum_{k=1}^{M} 4 n_{k}^{\mathrm{sp}}[r(t)]\left[\exp \left(B_{k} r(t)-A_{k}\right)-1\right] \Delta \nu_{k}
\end{aligned}
$$

where $h$ is the Plank's constant and indices $\mathrm{k}$ from 1 to $\mathrm{M}$ and $\mathrm{j}$ from $\mathrm{N}+1$ to $\mathrm{N}+\mathrm{M}$ represent the discretized ASE light, $\mathrm{j}=0$ represents the pump light and $\mathrm{j}$ from 1 to $\mathrm{N}$ the WDM signals; $\Delta \nu_{k}$ is the frequency resolution and the factor 4 represents two polarization components for both forward and backward ASE light. The spontaneous emission factor in (2) can be expressed as [4]

$$
n_{k}^{\mathrm{sp}}=\frac{g_{k} r(t)}{\left(g_{k}+\alpha_{k}\right) r(t)-\alpha_{k} r_{\max }}
$$

In (2)

$$
B_{j}=\frac{\alpha_{j}+g_{j}}{N_{\mathrm{Er}} A_{\mathrm{eff}}}=\frac{\alpha_{j}+g_{j}}{\xi \tau} ; \quad A_{j}=\alpha_{j} L
$$

where $A_{\text {eff }}$ is the active fiber effective area.

The time domain evolution of the WDM signals, ASE and pump lights at the amplifier output can be written as:

$$
P_{k}(L, t)=P_{k}(0, t) \exp G_{k}(t)
$$

where

$$
\begin{aligned}
G_{k}(t) & =\left(\alpha_{k}+g_{k}\right) \int_{0}^{L} N_{2} d t-\alpha_{k} L=\ln \frac{P_{k}(0, t)}{P_{k}(L, t)} \\
& =B_{k} r(t)-A_{k} .
\end{aligned}
$$

Equation (2) is numerically solved for EDFA-based WDM ring networks, including ASE light recirculation and its time domain variation. This is achieved by solving the time dependent reservoir equation for each EDFA over a time window much longer than the network round-trip time, in such a way that steady state conditions can be achieved at each EDFA output, following WDM channels add-drop operations.

The network is dynamically investigated starting from a stationary condition which is computed iteratively solving the steady-state amplifier propagation and rate equations. The time evolution of both WDM channels and ASE light recirculation is then computed considering a total time window which is a multiple of the network round-trip time. In particular, the solution is divided into a sequence of investigation time windows equal to the round trip time. During the first investigation time window the ASE spectrum at the input of the first amplifier, is initialized to the previously computed steady-state condition. The ASE light at the output of the last amplifier in the ring network becomes the new initial value of the ASE spectrum at the input of the first amplifier for the following loop analysis. This numerical procedure works well as long as the round-trip time is long enough to allow steady-state conditions to be reached in each time window of the sequence; this condition is always satisfied in practical cases, considering fiber spool of several tens of $\mathrm{km}$ between two consecutive EDFAs.

As we will show in detail in the following sections, this model allows us for a deep understanding of the physical mechanisms describing all-optical gain clamping in such looped optical networks.

\section{EXPERIMENTAl Setup FOR a Worst CASE SCENARIO ANALYSIS}

In this section we describe the experimental setup, shown in Fig. 1, which has been used for validating the dynamic model described in Section II; it reproduces a worst case scenario in term of transient effects, and can also be used for studying EDFA-based WDM ring network performances under different operation conditions [10].

Seven, high power, $100 \mathrm{GHz}$ ITU spaced DFB lasers (from $1552.52 \mathrm{~nm}$ to $1557.36 \mathrm{~nm}$ ) are multiplexed and switched on and off at low frequencies by an acouto-optic modulator (AOM), before being combined with a probe signal at $1551.72 \mathrm{~nm}$. Note that in order to reproduce adding and dropping of 23/24 channels, the power/channel of the seven loading signals is always chosen about $5 \mathrm{~dB}$ higher than the probe power $\left(10 \log _{10}(23 / 7)=5.16\right)$.

All WDM signals are then inserted into the ring, at the first EDFA input, and then propagated along the network before being extracted at the last EDFA output, through a fixed 8 channels add-drop multiplexer which leaves the ASE light to freely circulate in the ring. All EDFAs in the network have a simple structure, without gain equalizing filters, and are operated at constant pump power $(100 \mathrm{~mW}$ at $980 \mathrm{~nm})$.

To fully investigate the clamping mechanism provided by ASE light recirculation, the modulation period of the AOM should be much longer than the network round trip time; in 


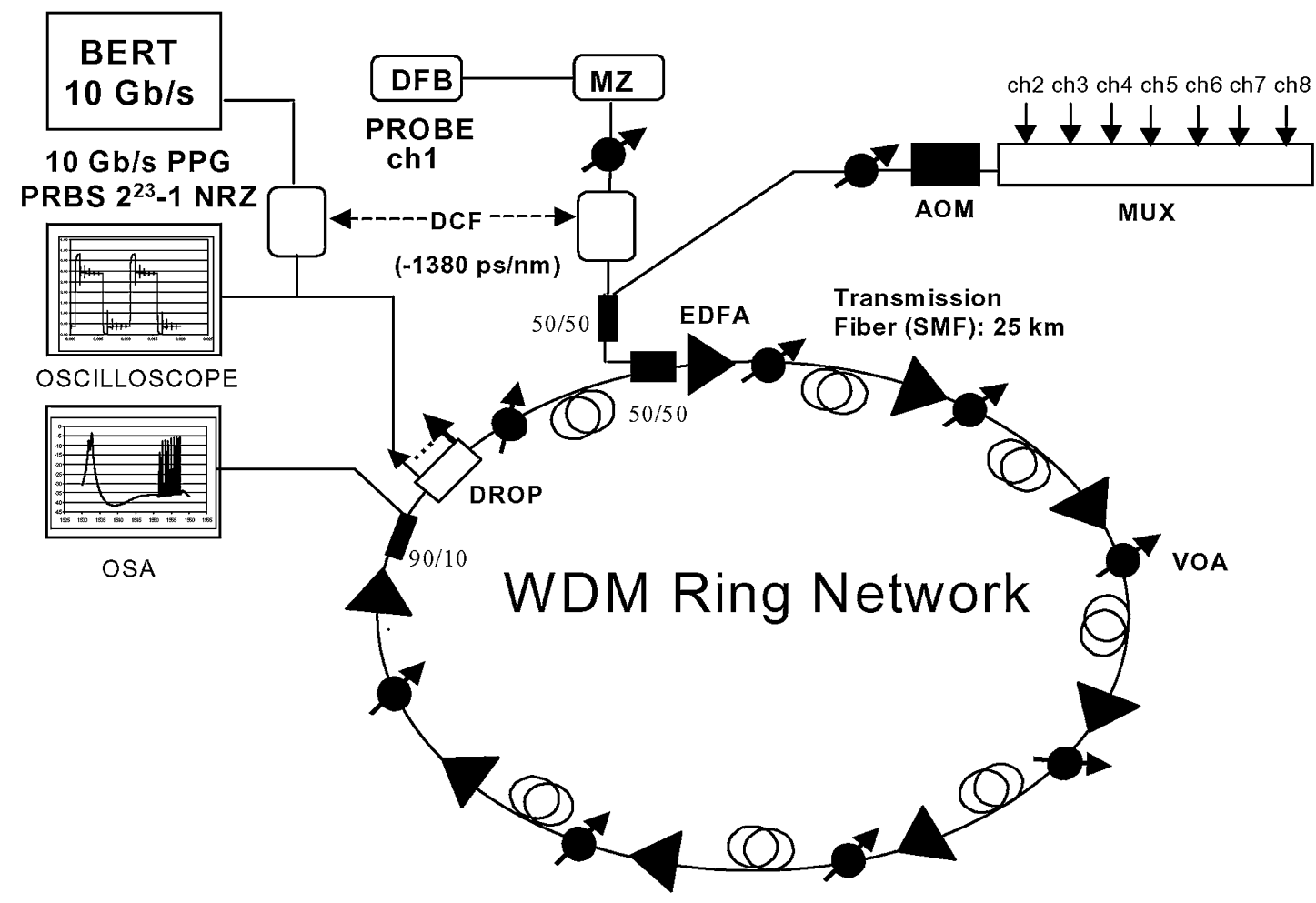

Fig. 1. Experimental set-up representing a worst case scenario.

particular, with seven sections of $25 \mathrm{~km}$ standard SM fiber, as shown in Fig. 1, the network round trip time is about $875 \mu \mathrm{s}$ and a modulation frequency of $100 \mathrm{~Hz}$ (period: $5 \mathrm{~ms}$ ) is low enough for the probe signal to reach staedy state conditions between consecutive WDM channels add and drop operations.

The setup shown in Fig. 1 allows us to measure the output spectrum, optical signal to noise ratio, the probe power transients induced by add-drop operations and probe bit-error rate (BER) performances at $10 \mathrm{~Gb} / \mathrm{s}$. Note that two dispersion compensating fiber spools $(-1380 \mathrm{ps} / \mathrm{nm})$ are introduced, respectively, at the transmitter and receiver side, to compensate almost exactly for the accumulated chromatic dispersion $(175 \mathrm{~km} \times$ $16 \mathrm{ps} / \mathrm{km} \mathrm{nm}=2800 \mathrm{ps} / \mathrm{nm})$. Variable optical attenuators (VOA) are used in each fiber span (25 km of standard SMF) and at the transmitter side in order to investigate network performances in different operation conditions such as varying the input power per channel and the span losses.

\section{VALIDATION OF THE MODEL}

The theoretical model described in Section II has been first validated for a single EDFA under WDM channels add-drop operations. The EDFA structure is very simple, consisting in about $10 \mathrm{~m}$ of alumina-silicate erbium-doped fiber (peak absorption: $8.5 \mathrm{~dB} / \mathrm{m}$ at $1532 \mathrm{~nm}$ ), bidirectionally pumped at $980 \mathrm{~nm}$ by a total pump power of $100 \mathrm{~mW}$ coupled into the active fiber. The intrinsic saturation fiber parameter $\xi$ has been obtained by measuring the saturation pump power $P_{p}^{\mathrm{sat}}$ at $980 \mathrm{~nm}(0.5 \mathrm{~mW})$ and using the equation:

$$
\zeta=\frac{P_{p}^{\mathrm{sat}} \alpha_{p}}{h \nu_{p}}
$$

where $\alpha_{p}$ is the pump absorption at frequency $\nu_{p}$ and $\mathrm{h}$ is the Plank constant.

The erbium metastable lifetime is $10 \mathrm{~ms}$ and pump absorption coefficient at $980 \mathrm{~nm}$ is $\alpha_{p}=4 \mathrm{~dB} / \mathrm{m}$.

In order the validate the single EDFA dynamic model under WDM channels add-drop operation a simple experiment has been carried out in which seven $100 \mathrm{GHz}$ ITU spaced WDM channels from 1549.32 to $1554.13 \mathrm{~nm}$, simulating a full amplifier load of 23 channels, are first modulated at low frequency by an AOM in order to reproduce WDM channels add-drop, and then combined with a CW probe signal at $1532.68 \mathrm{~nm}$ and coupled at the EDFA input. The probe transient behavior at the EDFA output is observed by filtering the signal at $1532.68 \mathrm{~nm}$ and using an oscilloscope.

The computed and measured probe rise $\left(\tau_{\text {drop }}\right)$ and fall $\left(\tau_{\text {add }}\right)$ times, defined as the transition times between $10 \%$ and $90 \%$ of the change in optical power, respectively, induced by WDM channels drop and add operations, are shown in Fig. 2 versus total amplifier input signal power. Good agreement between theory and experiment can be noted; add transients are faster than drop transients and while $\tau_{\text {add }}$ decreases, $\tau_{\text {drop }}$ increases with the total input signal power. The measured excursion level between full amplifier load condition (24 WDM channels) and probe channel only, is about $13 \mathrm{~dB}$, well in agreement with theoretical predictions. Note that the single EDFA dynamic model well predicts experimental results for other probe wavelengths as well.

The model has then been validated in steady-state conditions considering EDFA-based WDM ring networks with ASE light recirculation (the experimental setup is shown in Fig. 1). 


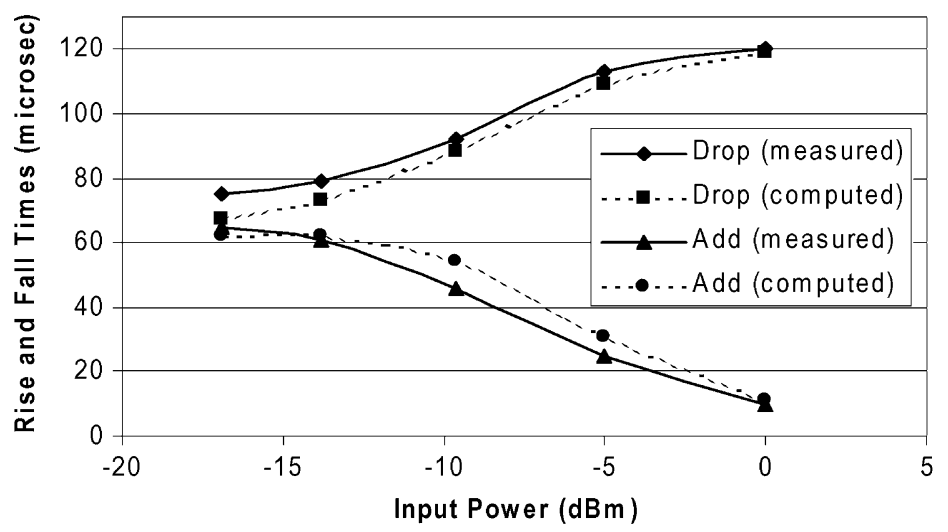

Fig. 2. Comparison between measured and computed rise and fall times.

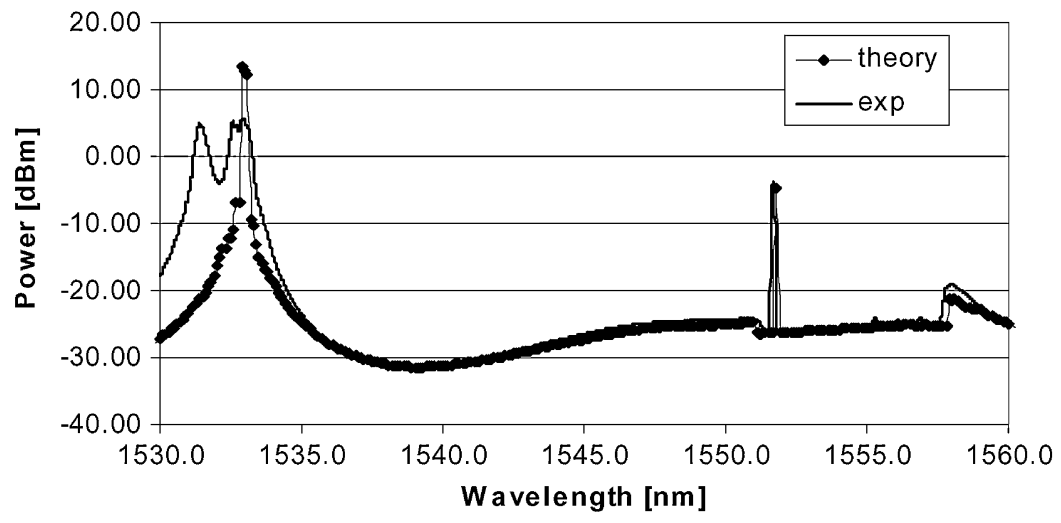

Fig. 3. Computed and measured output spectra from the last EDFA with span loss of $20 \mathrm{~dB}(8 \times 20 \mathrm{~dB})$.

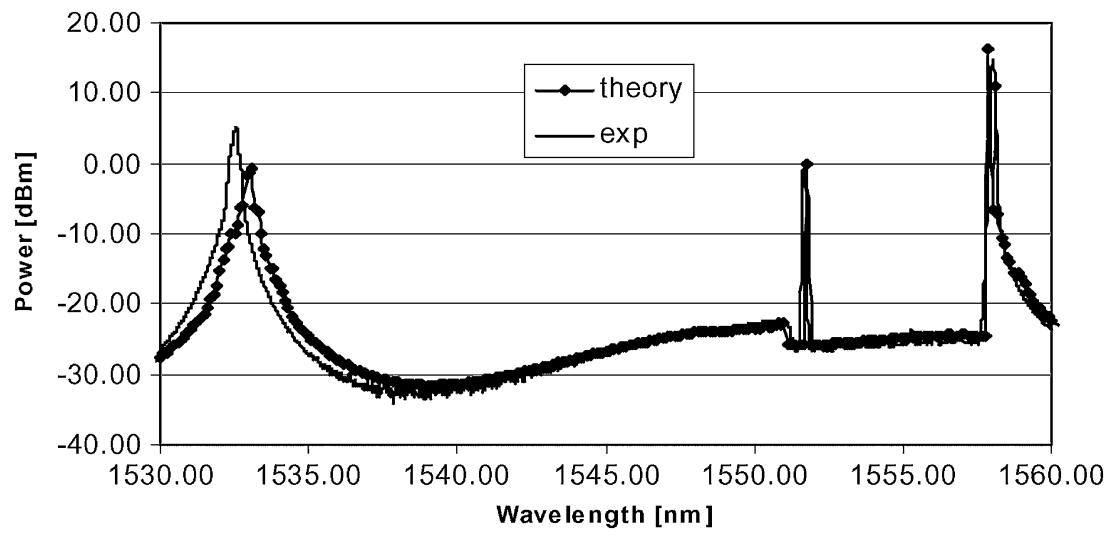

Fig. 4. Computed and measured output spectra from the last EDFA with span loss of $18.5 \mathrm{~dB}(8 \times 18.5 \mathrm{~dB})$.

Figs. 3 and 4 compare the spectra at the last EDFA output with only probe channel at $1551.72 \mathrm{~nm}$ and two different span losses (respectively, $8 \times 20 \mathrm{~dB}$ and $8 \times 18.5 \mathrm{~dB}$ ).

Although the theoretical model can not predict double gain peaking at around $1532 \mathrm{~nm}$, due to polarization effects [11] which are not included in the theory, good agreement can be observed between theoretical predictions and experimental results concerning ASE spectra distribution, output signal power, OSNR and gain peaking wavelength. Note that with shorter span losses $(18.5 \mathrm{~dB})$ gain peaking, due to ASE light recirculation in the ring, is competing between 1532 and $1560 \mathrm{~nm}$, as clearly shown in Fig. 4.
Finally, the dynamic model has been validated under adddrop operations, considering for the sake of simplicity only four fiber sections ( $25 \mathrm{~km}$ each) and four EDFAs. Fig. 5 compares the measured and computed probe transient behavior at the last EDFA output with a span loss of $20 \mathrm{~dB}$. To reproduce adding and dropping of $23 / 24 \mathrm{WDM}$ channels the probe power at the first EDFA input is $-20 \mathrm{dBm}$ and the input power for the seven channels, simulating the full network load, is $-15 \mathrm{dBm} / \mathrm{ch}$. From these results we can notice a maximum probe power overshoot $\left(\Delta \mathrm{P}_{\mathrm{TOT}}\right)$ of about $1 \mathrm{~dB}$, which is very small if compared with the strong power transient which would be expected in such a long EDFA chain without any gain control. 


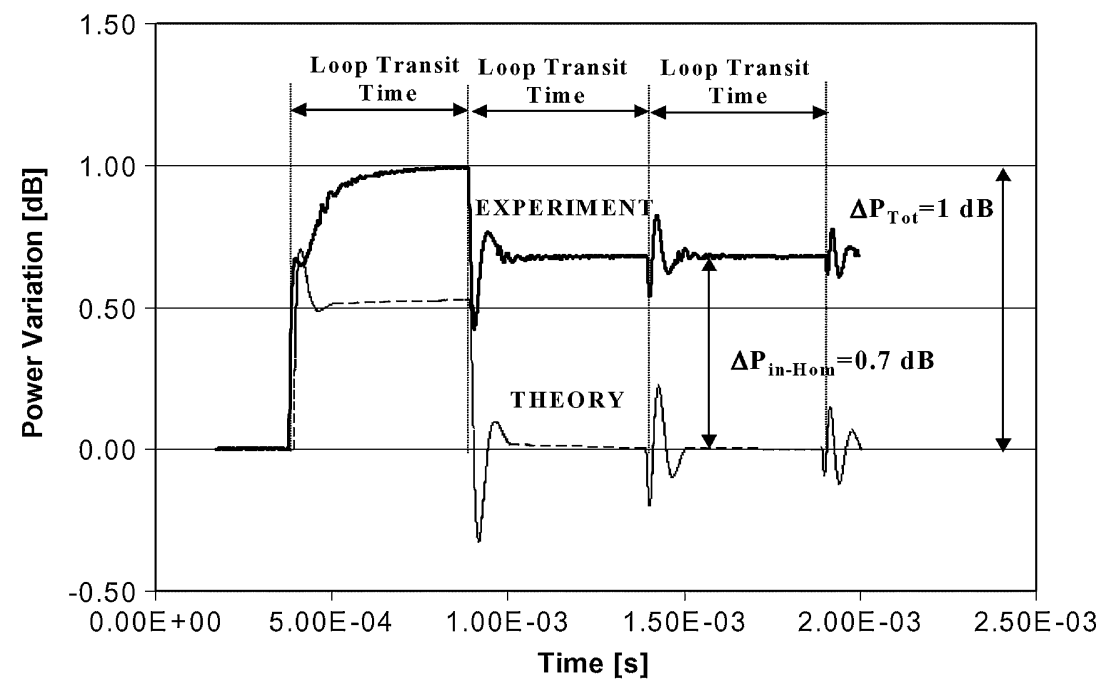

Fig. 5. Measured and computed probe transient behavior after $4 \times 20 \mathrm{~dB}$ dropping $23 / 24$ Channels.

Also note that after each loop transit time $(\approx 450 \mu \mathrm{s})$ the lasing ligth, recirculating along the ring, clamps the gain with typical probe power transients induced by the lasing relaxation oscillations. The clamping mechanism, provided by the ASE light recirculation, is only partially effective and the measured steady-state probe power levels with full channels load and only probe signal differ from the theoretical predictions $\left(\Delta \mathrm{P}_{\mathrm{TOT}}\right.$ and $\Delta \mathrm{P}_{\mathrm{IN}-\mathrm{HOM}}$ in Fig. 5 are, respectively, defined as the maximum probe power overshoot and the staedy-state probe power difference between the two conditions of full channels load and only probe signal).

These discrepancies between theory and experiment are mainly due to spectral hole burning and inhomogeneous gain [12] which hide the probe transients due to laser relaxation oscillations induced by the WDM channels drop. Note however that the comparisons shown in Fig. 5 confirm the presence of very limited probe power overshoots induced by WDM channels drop operations.

Although the model predictions are optimistic in terms of gain clamping effectiveness, with same steady-state probe power levels with and without loading channels, they are however very effective in designing EDFA-based WDM ring networks with ASE light recirculation, and provide important information for amplifier and network structure optimization.

\section{Network Performances}

In this section we first describe the physical mechanisms governing gain clamping in EDFA-based WDM ring networks with ASE light recirculation, and then we investigate network performances in terms of OSNR, relative intensity noise (RIN) transfer from lasing light to WDM signals, polarization effects and BER characteristics at $10 \mathrm{~Gb} / \mathrm{s}$.

We have studied the probe power transients at the last EDFA output, reproducing 23/24 WDM channels add-drop operations, as a function of the input power per channel at the first EDFA input. The span loss is $20 \mathrm{~dB}$, high enough to ensure stable gain peaking at around $1532 \mathrm{~nm}$, that is far enough from the WDM signal band, which would be from about 1542 to
$1561 \mathrm{~nm}$ with 24,100-GHz spaced channels. Note that, for a given EDFA structure and input power per channel, the span loss must be optimized in order to ensure the best compromise between good OSNR performances and lasing stability at around $1532 \mathrm{~nm}$, under full WDM channels add-drop operations. As we will show in details in the following sections, EDFA-based WDM ring networks self-stabiled by ASE light recirculation can achieve this best compromise considering quite high span losses, with a consequent degradation in the OSNR and network performances. In Section VI, we will point out that a very effective link control technique can be implemented, forcing a stable lasing action outside the WDM signal bandwidth without requiring high span losses; this technique provides better OSNR performances, ensuring at the same time good network stability and survivability.

Considering that the gain of the ring is equal to 1 at the gain peaking wavelength and less than 1 within the signal bandwidth, the maximum difference in the ring gain, $\Delta \mathrm{G}$, between gain peaking wavelength and WDM channel wavelengths, provides an important parameter for network and amplifier optimization. In particular while small $\Delta \mathrm{G}$ values (less than $1 \mathrm{~dB}$ ) reduces the WDM signal power losses in each span along the ring network ensuring good OSNR performances, higher $\Delta \mathrm{G}$ values (greater than $1 \mathrm{~dB}$ ) provide high network stability keeping the gain peaking wavelength steady in the position selected far from the channels. An optimum $\Delta \mathrm{G}$ value has been identified to be about $1 \mathrm{~dB}$.

Also note that introducing high-pass gain flattening filters within each EDFA allows one to force stable gain peaking at wavelengths close to the signal band, reducing at the same time the $\Delta \mathrm{G}$ values and consequently ensuring good OSNR performances as well as network stability. In addition, the combined use of high-pass gain flattening filters and link control techniques can provide great network stability with lower span losses further improving the OSNR performances.

Fig. 6 describes the measured maximum probe power overshoot $\left(\Delta \mathrm{P}_{\mathrm{TOT}}\right)$ and the steady-state power difference $\left(\Delta \mathrm{P}_{\mathrm{IN}-\mathrm{HOM}}\right)$, versus input power per channel at the first EDFA input, considering eight EDFAs and seven sections of 


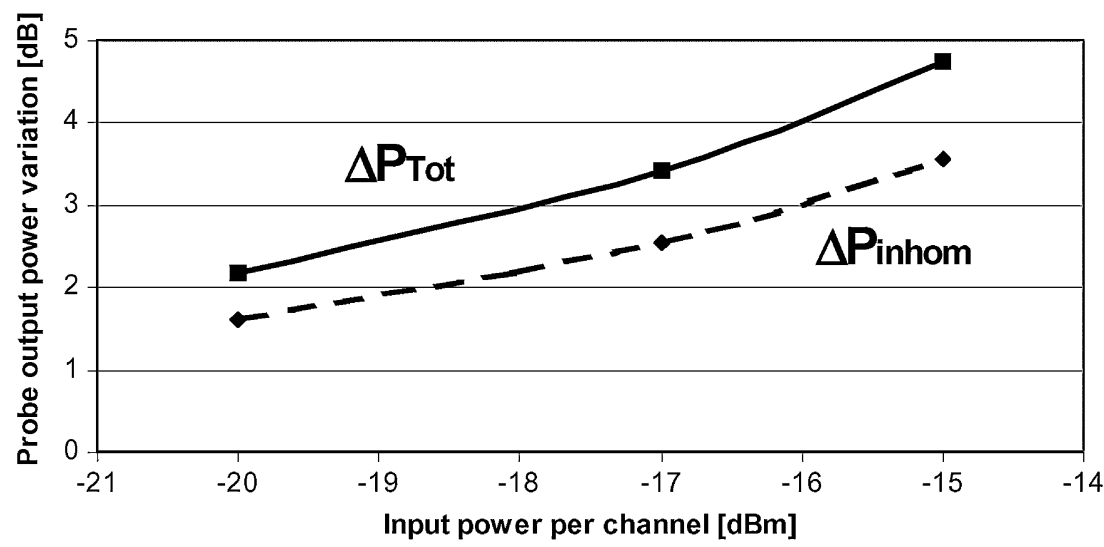

Fig. 6. Maximum probe output power overshoot after $8 \times 20 \mathrm{~dB}$ versus input signal power per channel.

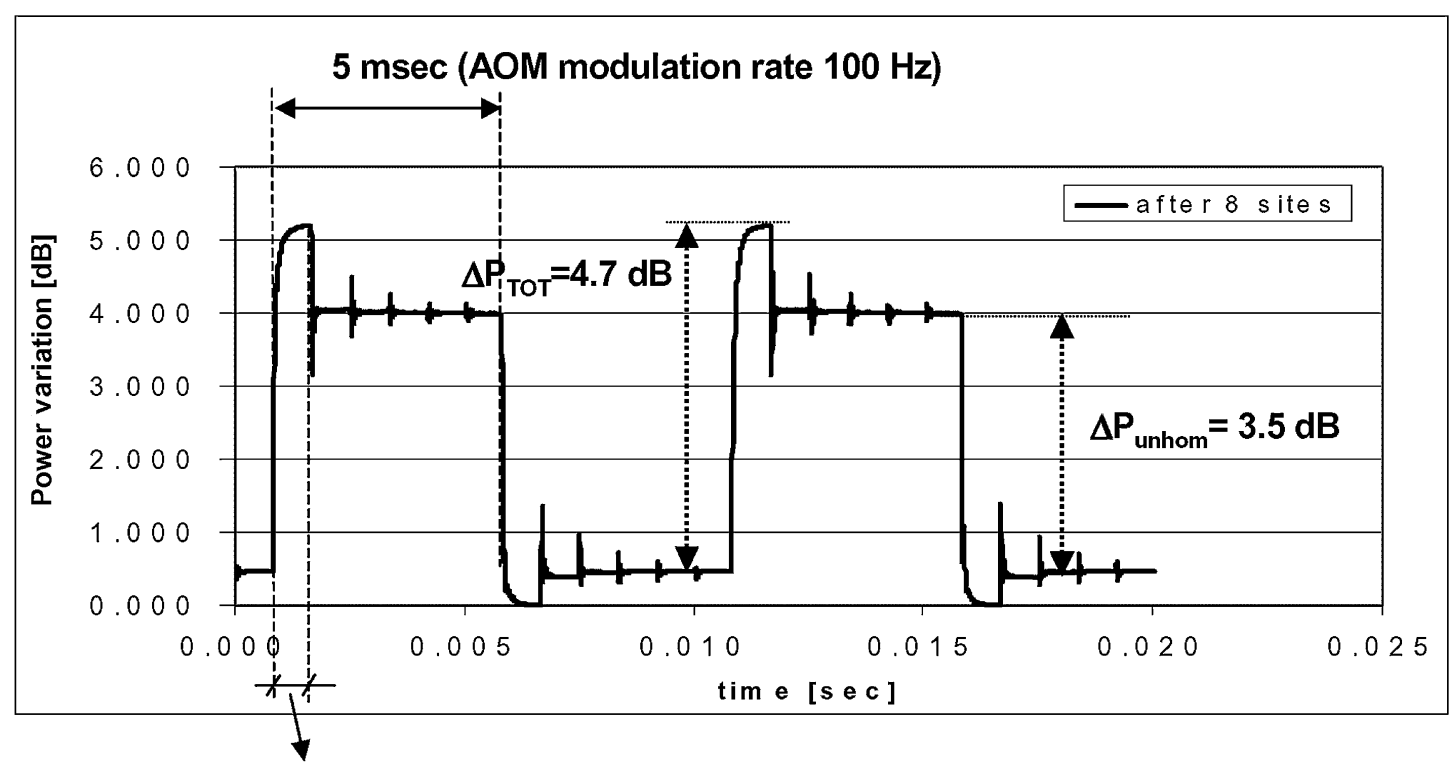

Loop transit time

Fig. 7. Measured probe output power dynamic behavior after $8 \times 20 \mathrm{~dB}$ with $-15 \mathrm{dBm} / \mathrm{ch}$.

$25 \mathrm{~km}$ standard SM fiber $(8 \times 20 \mathrm{~dB})$. Note that both $\Delta \mathrm{P}_{\text {TOT }}$ and $\Delta \mathrm{P}_{\mathrm{IN}-\mathrm{HOM}}$ grow with the input power per channel. This is due to the fact that the more the lasing light is predominant, compared to the total signal power, the more the clamping mechanism, provided by ASE light recirculation, is effective. As an example, Fig. 7 reports the probe power transient behavior at the last EDFA output with input power per channel of $-15 \mathrm{~dB} / \mathrm{ch}$ (the corresponding total input power is about $-1 \mathrm{dBm}$ ). Two different periodicities can be observed in the probe transient behavior, respectively, related to the clamping mechanism provided by ASE light recirculation, which follows the loop transit time, and to WDM channels add-drop operations which are simulated using an AOM with a given modulation rate.

Note that the measured transient effects shown in Figs. 7 and 8 do not show probe power over- and undershoots, induced by WDM channels drop and add operations typical of EDFA cascades; this is due to the presence of inhomogeneous effects and the large time scale used in the plots in order to show how steady-state conditions are reached between consecutive WDM channels add and drop operations.

We have, however, experimentally verified and confirmed by theory in Fig. 5, the presence of very limited power transients induced by add-drop operations when the network is self-stabilized by ASE light recirculation.

We have then investigated how transient effects depend on span losses. Fig. 8 shows the probe power transient at the last EDFA output, with $-17 \mathrm{dBm} / \mathrm{ch}$ and span loss of $18 \mathrm{~dB}$. From this figure and the output spectra at the last EDFA output with only probe channel, shown in Fig. 9, we can see that gain peaking is now competing between 1532 and $1560 \mathrm{~nm}$. This feature reduces spectral hole burning and inhomogenous effects, giving rise to lower steady-state power difference $\left(\Delta \mathrm{P}_{\mathrm{IN}-\mathrm{HOM}}\right)$.

Although short span losses improve the OSNR performance, they are not at all optimal in terms of network stability as the gain peaking wavelength can move, depending on the actual network load. 


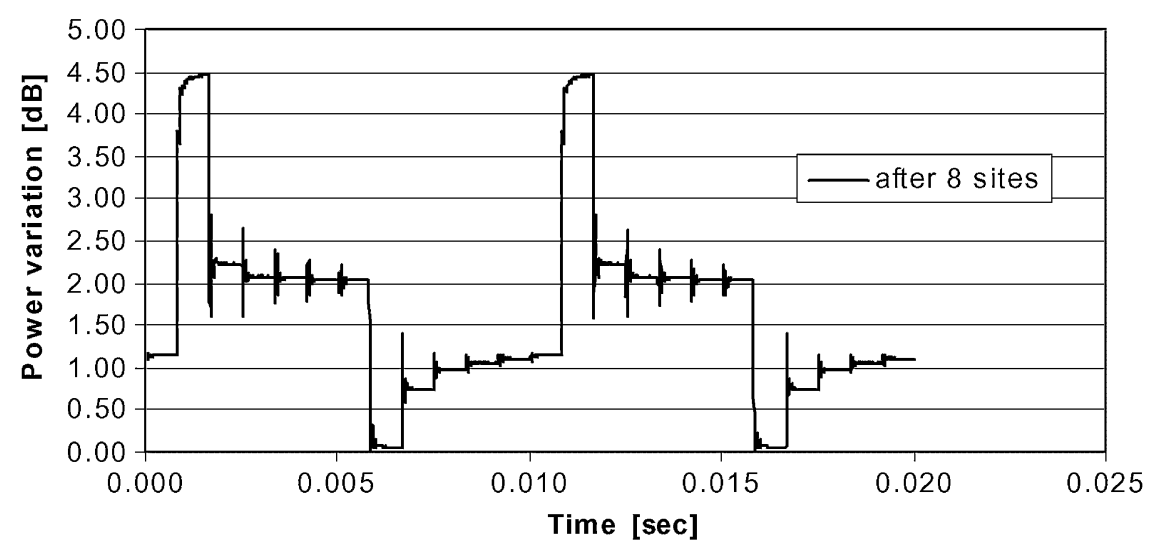

Fig. 8. Measured probe output power dynamic behavior after $8 \times 18 \mathrm{~dB}$ with $-17 \mathrm{dBm} / \mathrm{ch}$.

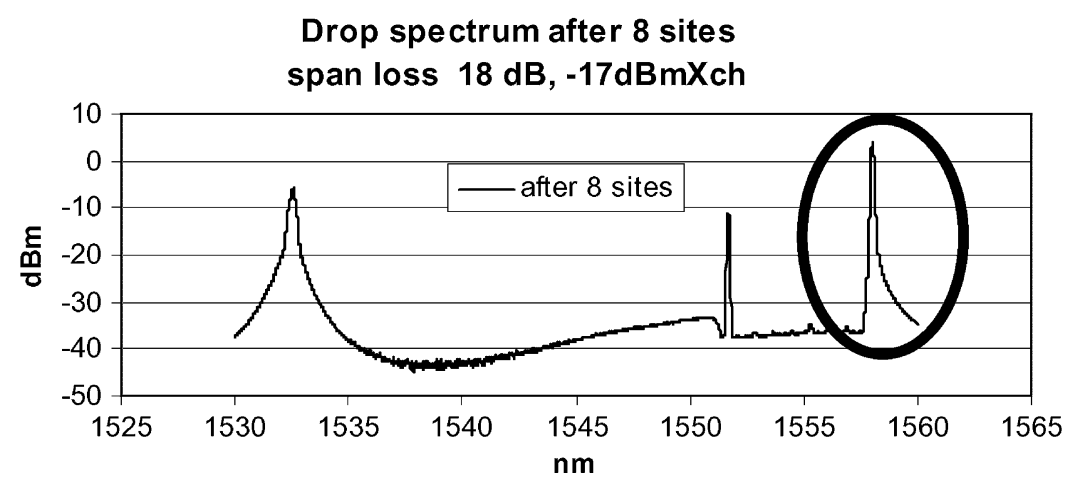

Fig. 9. Measured output spectrum after $8 \times 18 \mathrm{~dB}$ with probe channel at $-17 \mathrm{dBm} / \mathrm{ch}$.

TABLE I

MEASURED OSNR WITH $8 \times 20 \mathrm{~dB}$ SPAN LOSS AND $-17 \mathrm{dBm} / \mathrm{ch}$

\begin{tabular}{l|l|l|l|l|l|l|l|l|l}
\hline $\begin{array}{l}\lambda \mathrm{ch} \\
{[\mathrm{nm}]}\end{array}$ & 1542.1 & 1551.7 & 1552.5 & 1553.3 & 1554.1 & 1554.9 & 1555.7 & 1556.5 & 1557.3 \\
\hline $\begin{array}{l}\text { OSNR } \\
0.1[\mathrm{~dB}]\end{array}$ & 16.8 & 22.9 & 22.8 & 23.2 & 23.8 & 24.0 & 24.2 & 24.2 & 24.2 \\
\hline
\end{tabular}

In the following section we will describe a new link control technique which allows one to use short span losses, ensuring at the same time improved OSNR performances, great network robustness in terms of span loss variations and very limited power transients.

The network optical signal-to-noise ratio (SNR) performances have been experimentally investigated, showing that WDM channels in the lower wavelength region of the signal bandwidth experience poor OSNR performances.

Table I reports the measured OSNR over $0.1 \mathrm{~nm}$ resolution bandwidth after $8 \times 20 \mathrm{~dB}$ transmission along the ring network (an additional channel has been added at $1542 \mathrm{~nm}$ ). The OSNR over $0.1 \mathrm{~nm}$ resolution bandwidth is about $17 \mathrm{~dB}$ at the lower wavelength $1542 \mathrm{~nm}$, and greater than $24 \mathrm{~dB}$ above $1555 \mathrm{~nm}$.

Note that the EDFAs used in the experiments have not been optimized for particular application considered in this work; better OSNR performances can be achieved by amplifier optimization in terms of gain profile and flatness.

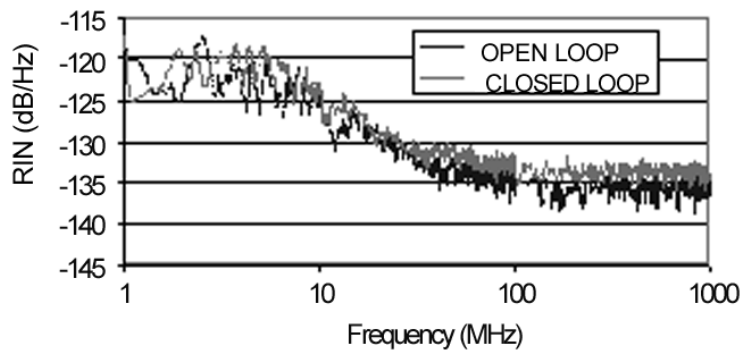

Fig. 10. Comparison between measured probe RIN with open and closed loop.

The maximum output OSNR variations, induced by polarization dependent effects, have been measured to be less than $0.7 \mathrm{~dB}$.

Also the probe relative intensity noise has been measured and compared with open and closed ring, at the same OSNR value: no penalties have been observed due to RIN transfer from laser light to signals, as can be observed in Fig. 10. This confirms that the transfer of noise into the signal channels is inefficient due to the slow EDFA dynamic [3].

However, to exclude possible potential transmission penalties, related to both probe power transients and noise transfer from lasing light to WDM channels, we have performed BER measurement at $10 \mathrm{~Gb} / \mathrm{s}$.

The probe signal has been externally modulated at $10 \mathrm{~Gb} / \mathrm{s}$ (PRBS $2^{23}-1$, NRZ format) and BER measurements versus received optical power and OSNR have been performed. 


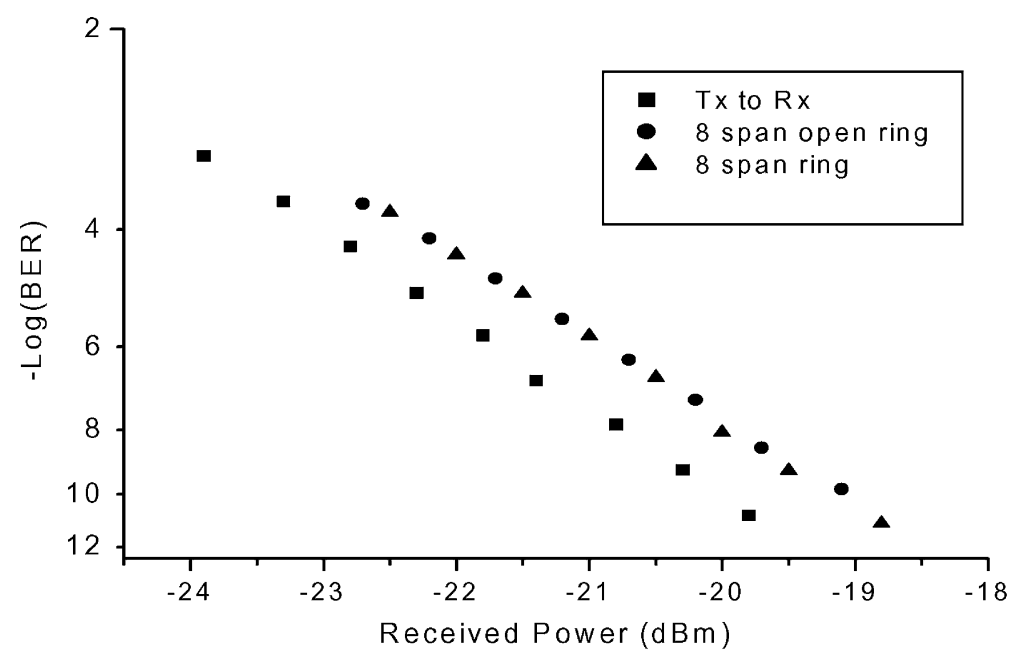

Fig. 11. BER versus received optical power in back-to-back, with $8 \times 20 \mathrm{~dB}$ span open loop and with $8 \times 20 \mathrm{~dB}$ span closed ring.

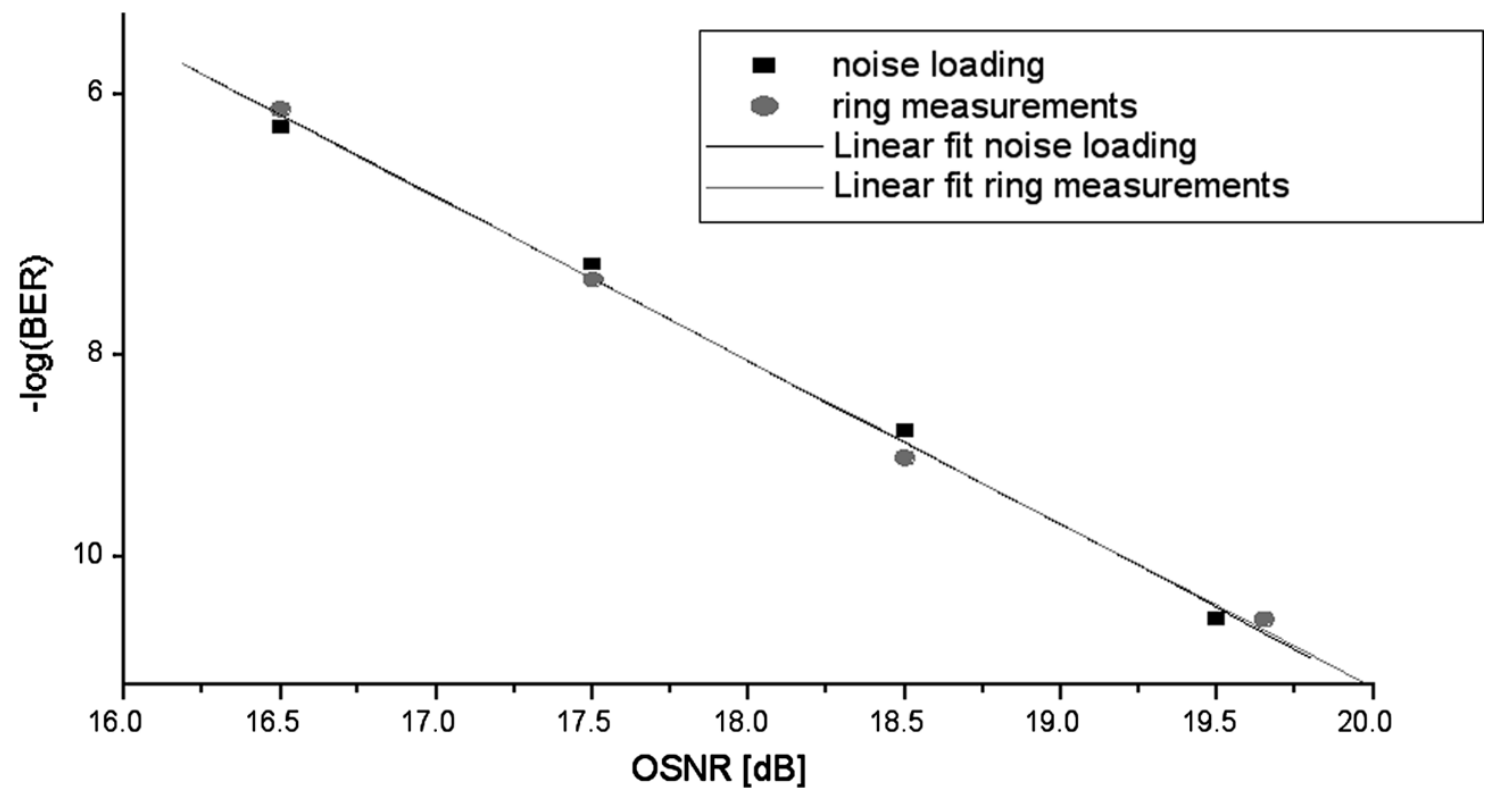

Fig. 12. BER versus average OSNR in back-to-back (noise loading) and with closed loop $(8 \times 20 \mathrm{~dB})$.

Fig. 11 reports the probe BER performances versus received power in back-to-back condition and with open and closed ring at the same OSNR value $(23 \mathrm{~dB})$. Note that BER performance in case of closed ring has been measured under WDM channels add-drop operations. No penalties have been observed due to the presence of ASE light recirculation.

The probe BER has also been measured versus OSNR values, in back-to-back condition (receiver characterization by noise loading) and with closed ring; the results, shown in Fig. 12 confirms that no transmission penalties have been observed under add-drop operations.

Note that as all EDFAs in the network are operated at constant pump power, without electronic output power control, we have not observed any chaotic oscillation due to lasing effects in closed cycles, as experimentally shown in [13], where instabilities were likely induced by electronically controlled channel power equalizers. However, the results shown in [13] suggest that, in order to avoid resonances related to the round-trip network transit time and consequent potential chaotic oscillations, care must be taken in introducing electronically controlled components in EDFA-based WDM ring networks with ASE light recirculation.

\section{Link CONTROL AND NeTwORK SURVIVABILITY}

In this section we investigate how link control techniques [6], [7] can be used in EDFA-based WDM ring networks with ASE light recirculation, in order to provide network robustness in terms of span loss variations, limited power transients, improved OSNR performance and, at the same time, high network survivability in case of fiber or EDFA breakage.

We propose to inject a laser beam at a given amplifier node of the ring network, and leave it free to circulate in the loop.

Fig. 13 shows the experimental setup we have used to investigate the proposed link control technique. 


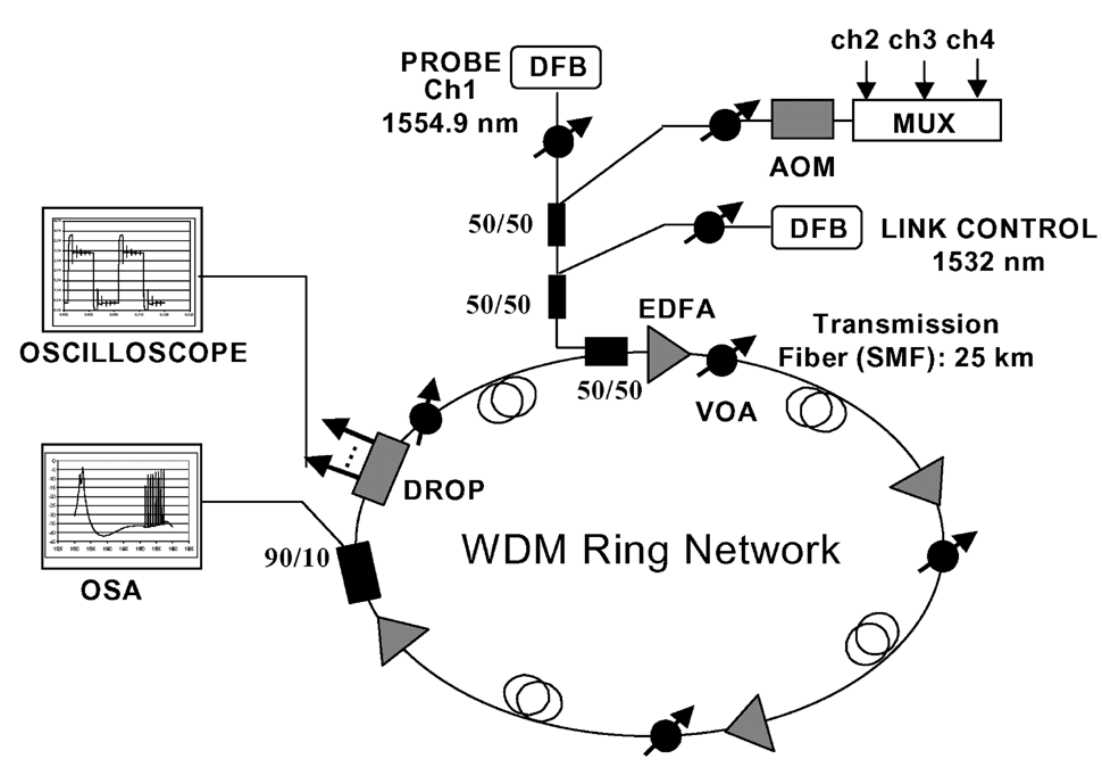

Fig. 13. Experimental setup for EDFA-based WDM ring network with ASE light recirculation and link control.

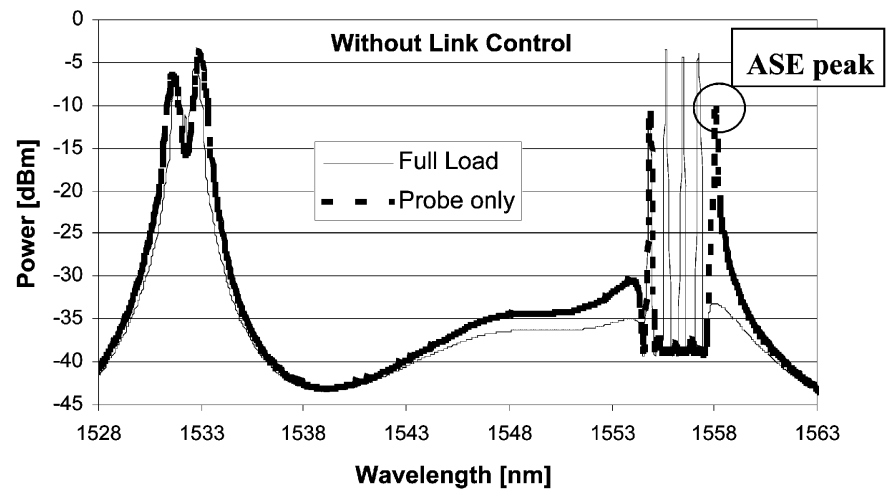

Fig. 14. Output spectra without link control.

For the sake of simplicity, only four sections of $25 \mathrm{~km}$ standard SM fiber and four EDFAs, operating at constant pump power $(100 \mathrm{~mW}$ at $980 \mathrm{~nm})$ were used. Three high power channels are multiplexed and switched on and off at $100 \mathrm{~Hz}$, by an acoustooptic modulator, to simulate adding and dropping of 15/16 WDM channels, before being combined with a probe signal at $1554.9 \mathrm{~nm}$. The probe dynamic behavior was observed after propagation along the entire looped network, with and without link control at $1532 \mathrm{~nm}$, provided by a DFB laser which is also coupled into the network at the first EDFA input. Note that both link control and ASE light are free to circulate in the loop, while the three loading channels and probe signal are extracted at the last EDFA output by a fixed four channel add-drop multiplexer.

Figs. 14 and 15 show the output spectra with full network load and single probe channel at $-20 \mathrm{dBm}$, respectively, with and without link control. The network span budget $(4 \times 19 \mathrm{~dB})$ is such that, without link control, gain peaking can form within the WDM signal band, depending on the actual network load.

On the other hand, with link control, gain peaking is stable at $1532 \mathrm{~nm}$. Note that the relative low loss of each span $(19 \mathrm{~dB})$ is advantageous in terms of OSNR performance but is not at all op- timal in terms of dynamic behavior and network stability. Fig. 16 compares the probe transient behavior at the last EDFA output, with and without link control; larger power transients are present in the network only based on ASE light recirculation, and higher span losses would be required in this case, in order to ensure steady operation conditions, avoiding gain peaking competition at different wavelengths. Satisfying this requirement would ensure stability of the ring.

It can also be noted that the link at $1532 \mathrm{~nm}$ avoids formation of a double ASE peak at around $1532 \mathrm{~nm}$, providing higher robustness to polarization dependent effects. The use of link control techniques also allows one to perform, with limited additional cost, a node amplifier structure which can guarantee network survivability. Basically, each amplifier node can be equipped with a DFB laser which can be activated in case of network failure, caused by fiber or EDFA break. As shown in the inset of Fig. 17, a network failure can be easily detected in each node by splitting a small fraction of the total power at the EDFA input, and recognizing the presence of lasing light at around $1532 \mathrm{~nm}$ within the loop. If the lasing light falls below a given threshold, the DFB laser is switched on. Note that with a 2-nm filter bandwidth in the detection scheme, and with an amplifier design which ensures a total lasing light $3 \mathrm{~dB}$ above the total power of all WDM channels in normal operation conditions (i.e., with ASE light recirculation), the power difference between lasing light in normal operation and ASE light falling within the filter bandwidth in case of fiber or EDFA break, is always greater than $10 \mathrm{~dB}$; this ensures an easy threshold selection in the detection circuit.

We have investigated this network scenario using the experimentally validated dynamic model previously described, which includes both ASE light recirculation and link control in EDFAbased WDM ring networks. Fig. 17 compares the computed probe transient effects, respectively, with and without network survivability scheme, at the last amplifier output of a ring network, composed of eight sections of 25-km SM fibers and eight EDFA. 


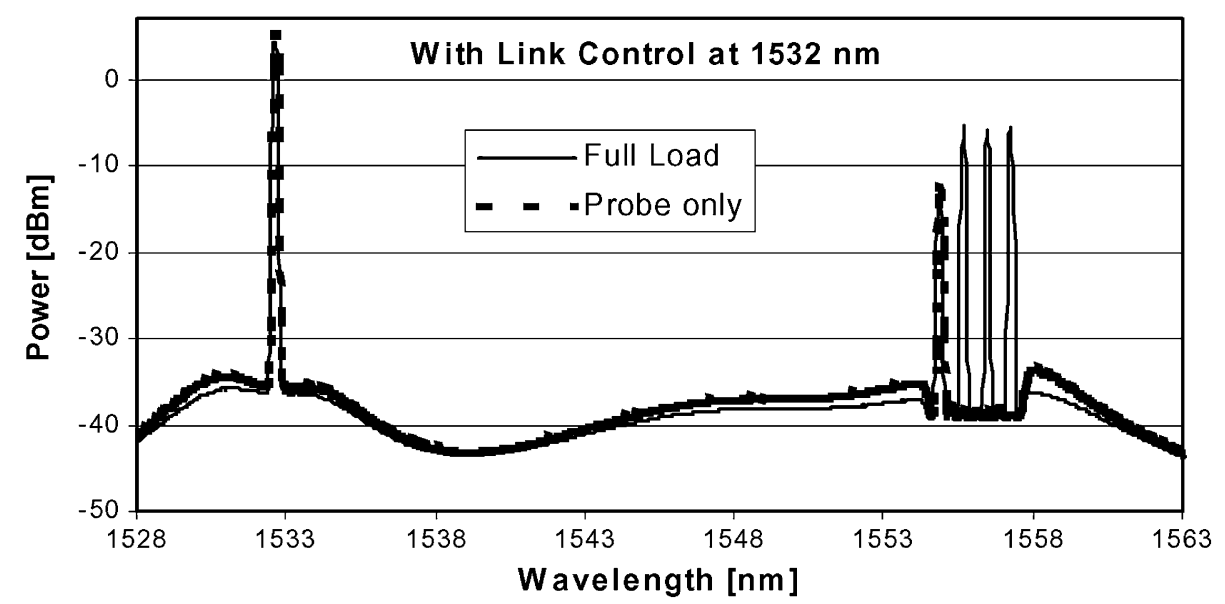

Fig. 15. Output spectra with link control.

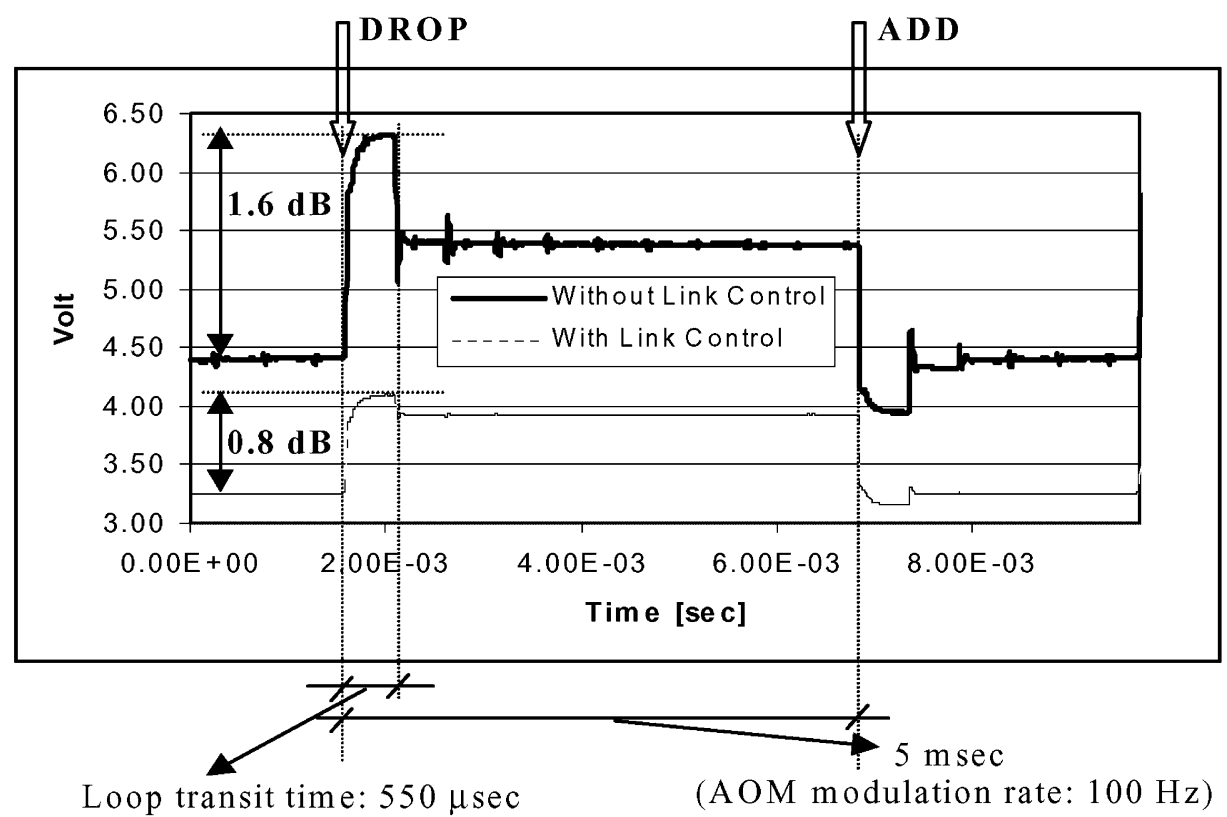

Fig. 16. Probe transient behavior with and without link control.

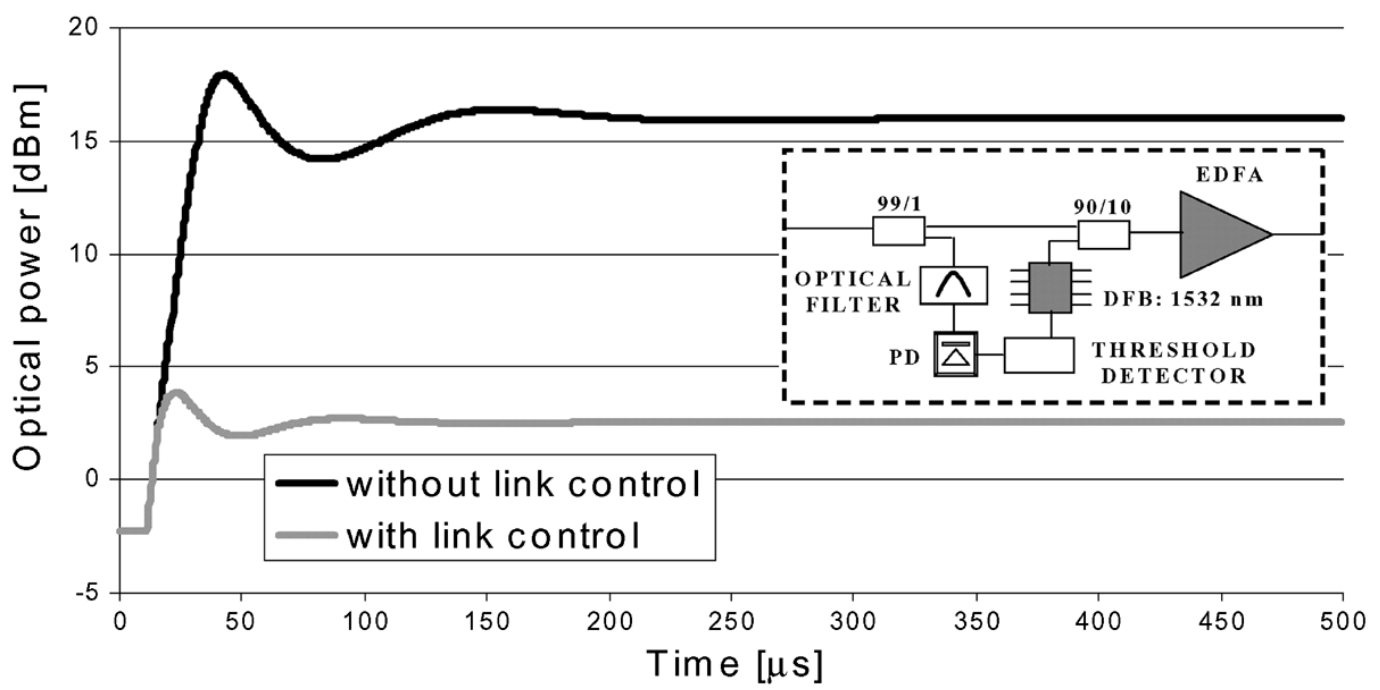

Fig. 17. Computed probe power transient at the last EDFA output following a fiber break, with and without link control for network survivability (the inset shows the detection scheme for network failure). 
The network works in normal operation condition with ASE light recirculation, without link control. Following a fiber break, supposed to be instantaneous (worst case scenario), the first amplifier node after the EDFA break will activate the corresponding DFB laser at $-10 \mathrm{dBm}$, with a delay of $5 \mu \mathrm{s}$, caused by the electronic circuit implementing the threshold detector. It is clear from Fig. 17 that the proposed scheme effectively prevents large signal power excursions ensuring network survivability.

\section{CONCLUSION}

In conclusion, we have theoretically and experimentally investigated the performances of EDFA-based WDM ring network in which gain clamping is automatically achieved by free ASE light recirculation. We have shown that a proper network and amplifier design makes these networks robust to WDM channels add-drop operations, greatly simplifying network management and control. No transmission penalties, due to ASE recirculation have been experimentally observed. A new link control technique for EDFA-based WDM ring networks with ASE light recirculation has also been proposed and demonstrated; it provides great network robustness in terms of span loss variations, very limited power transients and improved OSNR performance. Moreover, this link control can also be exploited to guarantee high network survivability in case of fiber or EDFA breakage.

\section{ACKNOWLEDGMENT}

The authors would like to acknowledge P. Ghiggino for helpful discussions and suggestions.

\section{REFERENCES}

[1] M. Islam, Raman Amplifiers for Telecommunications 1, Physical Principles and Raman Amplifiers for Telecommunications 2, Sub-Systems and Systems. New York: Springer-Verlag, 2003.

[2] P. Iannone and K. Reichmann, "In-service up-grade of an amplified 130-km metro CWDM transmission systems using single LOA with $140 \mathrm{~nm}$ bandwidth," in OFC, Atlanta, GA, 2003. paper ThQ3.

[3] Y. Sun, A. K. Srivastava, J. L. Zyskind, J. W. Sulhoff, T. A. Strasser, C. Wolf, and J. R. Pedrazzani, "Signal power variations in optically amplified WDM ring networks," in ECOC, 1997, pp. 135-137.

[4] M. Karasek, A. Bononi, L. R. Rusch, and M. Menif, "Gain stabilization in gain clamped EDFA cascades fed by WDM burst-mode packet traffic," J. Lightw. Technol., vol. 18, no. 3, pp. 308-313, Mar. 2000

[5] W. Xin, G. K. Chang, B. W. Meagher, S. J. B. Yoo, J. L. Jackel, J. C. Young, H. Dai, and G. Ellinas, "Chaotic lasing effect in a closed cycle in transparent wavelength division multiplexed networks," in $O F C, 1999$, pp. 246-248. paper TuR1-1.

[6] A. K. Srivastava, J. L. Zyskind, Y. Sun, J. Ellson, G. Newsome, R. W. Tkach, A. R. Chraplyvy, J. W. Sulhoff, T. A. Strasser, C. Wolf, and J. R. Pedrazzani, "Fast-link control protection of surviving channels in multiwavelength optical networks," IEEE Photon. Technol. Lett., vol. 9, no. 12, pp. 1667-1669, Dec. 1997.

[7] G. Sacchi, S. Sugliani, A. Bogoni, A. D’Errico, F. Di Pasquale, R. Di Muro, R. Magri, G. Bruno, and F. Cavaliere, "Link control and survivability in EDFA based WDM ring networks with ASE light re-circulation," in ECOC, Stokolm, Sweden, 2004. paper We4.P.082.

[8] A. Bononi and L. A. Rusch, "Doped-fiber amplifier dynamics: A system perspective," J. Lightw. Technol., vol. 16, no. 5, pp. 945-956, May 1998.
[9] C. R. Giles, C. A. Burrus, D. J. Di Giovanni, N. K. Dutta, and G. Raybon, "Characterization of erbium-doped fibers and applications to modeling 980-nm and 1480-nm pumped amplifiers," IEEE Photon. Technol. Lett., vol. 3, no. 4, pp. 363-365, Apr. 1991.

[10] G. Sacchi, S. Sugliani, A. Bogoni, A. D’Errico, F. Di Pasquale, R. Di Muro, R. Magri, G. Bruno, and F. Cavaliere, "Effective transient control by free ASE light re-circulation in EDFA based WDM ring networks," in OpNeTec, Pisa, Italy, 2004. paper P9.

[11] V. J. Mazurczyk and J. L. Zyskind, "Polarization dependent gain in erbium-doped fiber amplifiers," IEEE Photon. Technol. Lett., vol. 6, no. 5, pp. 616-618, May 1994.

[12] G. Luo, J. L. Zyskind, J. A. Nagel, and M. A. Ali, "Experimental and theoretical analysis of relaxation-oscillations and spectral hole burning effects in all-optical gain-clamped EDFA's for WDM networks," J. Lightw. Technol., vol. 16, no. 4, pp. 527-533, Apr. 1998.

[13] P. Kim, S. Bae, J. Kim, H. Choi, S. J. Ahn, H. G. Woo, and N. Park, "Analysis of the network oscillations in the amplified WDM ring network-Dependency on the channel power equalizer speed and network span length," in $O F C, 2000$, pp. 59-61. paper ThD6-1.

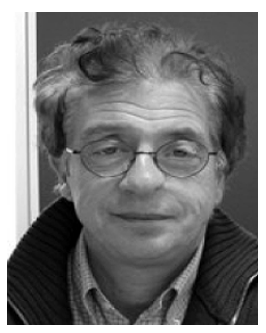

G. Sacchi was born in Milan, Italy, in 1949. He received the physics degree from the University of Milan, Milan, Italy, in 1979.

From 1980 to 1997, he worked for Italtel, Milan, Italy, as a Photonic Components Manager. From 1997 to 2000, he was an Optical Amplifier Designer with Pirelli Cavi, Milan, Italy. From 2000 to 2002, he was a Senior Researcher with Cisco Photonics, Monza, Italy. Since 2002, he has been a Researcher at Consorzio Nazionale Interuniversitario per le Telecomunicazioni (CNIT), Pisa, Italy. He has filed ten international patents, and he is the author and coauthor of more than 20 scientific journal and conference papers in the area of optical amplifiers and optical communications systems. His research interests are in the area of optical amplifiers and fiber-optic transmissions.

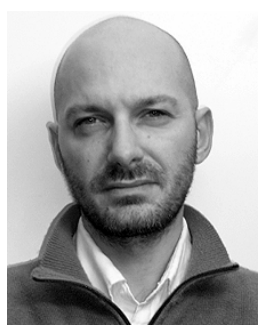

S. Sugliani was born in Bergamo, Italy, in 1972. $\mathrm{He}$ received the materials engineering degree and the Master's degree in optical systems and networks from the Politecnico di Milano, Milan, Italy, in 1999 and 2001, respectively.

Since 2002, he has been a Research Assistant with the Photonic Networks National Laboratory, Consorzio Nazionale Interuniversitario per le Telecomunicazioni (CNIT), Pisa, Italy. His current research interests include optical amplification and fiber-optic systems.

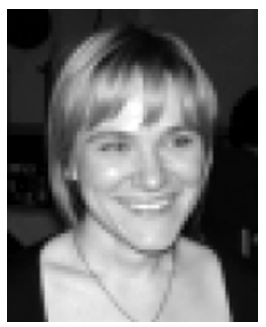

A. Bogoni was born in Mantova, Italy, in 1972. She received the Dr.Ing. degree in electronics engineering and the Ph.D. degree from the University of Parma, Parma, Italy, in 1997 and 2004, respectively.

From 1998 to 1999, she was grantee of Marconi S.p.a. at the University of Parma in the Optic Communications Laboratory. Since 2000, she has been a Researcher at the Consorzio Nazionale Interuniversitario per le Telecomunicazioni (CNIT), Pisa, Italy. From 2000 to 2001, she worked in the Parma university laboratory, and since 2002 , she has been a Senior Researcher at the National Photonic Networks National Laboratory, CNIT. Her research interests are in the area of fiber-optic transmissions. 


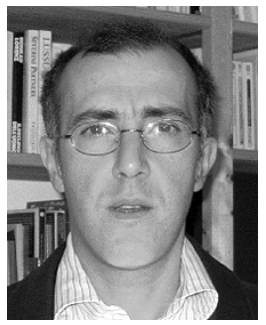

F. Di Pasquale (M'03) was born in Italy in 1963 . He received the electronic engineering degree from the University of Bologna, Bologna, Italy, in 1989 and the Ph.D. degree in information technology from the University of Parma, Parma, Italy, in 1993.

From 1993 to 1998, he was a Research Fellow with the Department of Electrical and Electronic Engineering, University College London, London, U.K., working on optical amplifiers, wavelength-division-multiplexing (WDM) optical communication systems, and liquid-crystal displays. After two years with Pirelli Cavi e Sistemi and two years with Cisco Photonics Italy, he is now Associate Professor in telecommunications at the Scuola Superiore Sant'Anna di Studi Universitari e Perfezionamento, Pisa, Italy. His current research interests include Raman amplifiers, erbium-doped fiber amplifiers (EDFAs), and their applications in WDM communication systems and networks. He has filed 15 international patents, and he is the author and coauthor of more than 60 scientific journal and conference papers in the area of optical amplifiers, optical communications systems, and liquid-crystal displays.

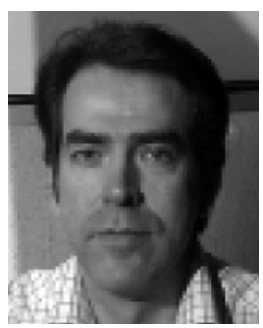

R. Di Muro received the first-class honors degree in electronics engineering from the University of Bologna, Bologna, Italy, in 1992. He received the $\mathrm{Ph} . \mathrm{D}$. degree from the University of Parma, Parma, Italy, in 1996 working on the analysis of nonlinear optics effects in components and optical devices. He is currently working toward an evening Executive Master's in Business Administration (EMBA) at Warwick University, Warwick, U.K.

He taught high-level electronics and math at the University of Parma for more than one year. In 1996, he joined the University College London, London, U.K., where he worked on praseodimium-doped fiber amplifiers (PDFAs) and analysis of four-wave mixing in wavelength-division multiplexing (WDM) operating at $1300 \mathrm{~nm}$. From 1996 to 1997, he was with the Ecole Nationale Supirieure des Tilicommunications-Telecom Paris, France, where he worked on soliton systems in optical communication at $1550 \mathrm{~nm}$ for a high bit rate. In 1997, he joined the Advanced Technology Centre in Nortel plc, Harlow, Essex, U.K., where he worked on the design and characterization of an extended band amplifier. In 1999, he was an Amplifier Design and Product Engineer in the optoelectronic manufacturing division of Nortel Networks, Paignton, Devon, U.K. In 2000, he rejoined the Amplifier Group of Nortel Networks, Harlow, Essex, U.K., as a Leader in system propagation and amplifiers research for new applications such as short-wavelength bands. Since 2001, he has been a Photonic Strategist with Marconi Corporation plc, Coventry, U.K. He collaborates with European universities for long-term research. He has published 30 papers in conferences and technical publications and has submitted 11 patents in the area of communications and amplification.
R. Magri, photograph and biography not available at the time of publication.

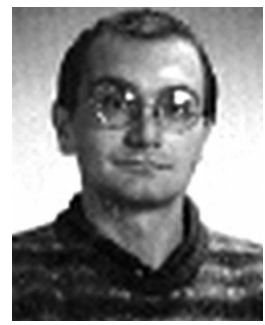

G. Bruno received the electrical engineering degree from the University of Genova, Genova, Italy.

In 2000, he joined the Transmission Modeling and System Design Group in Marconi Communications, Optical Networks, Genova, Italy, where he served as a Modeling Engineer, taking part in the development and deployment of the wavelength-division-multiplexing (WDM) long-haul product line. $\mathrm{He}$ is currently working on the modeling and network planning activity for the new generation of metro systems. His research interests include numerical modeling and simulation and network design problems in optical networks.

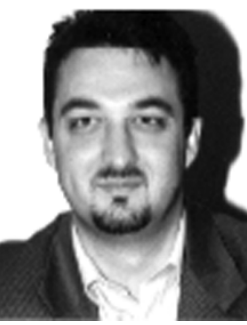

F. Cavaliere was born in Cosenza, Italy, in $1970 . \mathrm{He}$ received the Dr.Ing. degree in telecommunications engineering from the University of Pisa, Pisa, Italy, in 1996.

Since 1998, he has worked for Marconi Corporation plc. He is currently a Senior Engineer of the Transmission and Network Modeling Team at the Marconi Photonics Technology Research Center, Pisa, Italy. His research interests are in the design and modeling of wavelength-division-multiplexing (WDM) optical communication systems. 